This item was submitted to Loughborough's Research Repository by the author.

Items in Figshare are protected by copyright, with all rights reserved, unless otherwise indicated.

\title{
Analysing the viability of business networks in multinational organisations: a case study of the aerospace and defence industry
}

\section{PLEASE CITE THE PUBLISHED VERSION}

http://dx.doi.org/10.1142/S0219649214500233

\section{PUBLISHER}

(C) World Scientific Publishing

\section{VERSION}

AM (Accepted Manuscript)

\section{PUBLISHER STATEMENT}

This work is made available according to the conditions of the Creative Commons Attribution-NonCommercialNoDerivatives 4.0 International (CC BY-NC-ND 4.0) licence. Full details of this licence are available at: https://creativecommons.org/licenses/by-nc-nd/4.0/

\section{LICENCE}

CC BY-NC-ND 4.0

\section{REPOSITORY RECORD}

Israilidis, John, Louise Cooke, and Russell Lock. 2019. "Analysing the Viability of Business Networks in Multinational Organisations: A Case Study of the Aerospace and Defence Industry”. figshare. https://hdl.handle.net/2134/16933. 


\title{
Analysing the viability of business networks in multinational organisations: a case study of the Aerospace and Defence industry
}

\author{
John Israilidis $^{\dagger}$ \\ Business School, Staffordshire University, UK \\ Louise Cooke \\ School of Business and Economics, Loughborough University, UK \\ Russell Lock \\ Department of Computer Science, Loughborough University, UK
}

\begin{abstract}
This paper outlines ways of increasing the productivity and performance of organisational networks within multinational corporations. It explores their heterogeneous knowledge structures, while analysing their strengths and weaknesses. The research examines the collaborative knowledge networks of one of the largest multinational defence and aerospace organisations in the world and adopts an interpretivist philosophy, using a qualitative research methodology. This study argues that, both informal and formal business networks should be supported by management to enhance knowledge sharing between different groups within multinational organisations. It also argues that, knowledge sharing policies should be reviewed on an on-going basis in order to create a robust network of networks while acknowledging the importance of smaller and more isolated knowledge exchange communities.
\end{abstract}

Keywords: Business networks; collaboration; multinational organisations; corporate strategies; performance improvement.

\footnotetext{
${ }^{\dagger}$ Correspondence: Dr. John Israilidis, Business School, Staffordshire University, Leek Road, Stoke-on-Trent ST4 2DF, United Kingdom; Email: j.israilidis@staffs.ac.uk
} 


\section{Introduction}

The purpose of this paper is to report on collaborative knowledge communities, also referred to as business networks, to analyse their productivity and performance within technology intensive settings. Particularly, this study explores the heterogeneous knowledge structures of such networks, while exploring their strengths and weaknesses using relevant performance indicators. The literature has commented on a variety of topics related to business network analysis (Hansen 2002); however, the focus here is on the development of holistic knowledge sharing communities within multinational organisations, as this is especially important for boosting internal communications and individual capabilities, and can be viewed as an on-going performance evaluation for employees and large organisations.

Multinational organisations often show levels of stress as a result of ineffective knowledge transfer mechanisms (Sun and Scott 2005). Consequently, many attempts have been made to improve business performance and cut operational costs by developing collaborative networks and other communities of practice. In general, the creation and support of business networks can have a significant positive impact on the way information and knowledge is transferred within a company (Wenger et al. 2002). It has been highlighted by academics (Zhao and Aram 1995; Wenger et al. 2002) and practitioners that such networks can help support businesses' operations and lead to new business opportunities. Also, business networks could protect the organisation from potential external threats and determine actions to mitigate risk. For example as Aldrich et al. (1987) state, by analysing the business networks of an organisation together with their relationships 
with other organisations we can logically deduce characteristics regarding the organisation's behaviour and decision making.

Granovetter (1985) noted the importance of business networks in the economic stability and development of a company. His study, based on the premise that each activity is undertaken by a network of actors working in collaboration with each other, identified that the interactions and communications of employees working in a team can affect the knowledge activities made within the organisation. In addition, a previous study focusing on the dynamics of business networks (Granovetter 1973) makes a differentiation between strong and weak ties that such networks may have (for example, the frequency of communication within the network). In an organisational context, it is common to establish some strong business links with many weak ties. The weak connections can help to create new business links and bring new knowledge into the organisation. As Burt (1992) noted, establishing weak ties is essential to build stronger links and develop a collaborative knowledge network. Furthermore, one of the main concepts in Marshall's (1965) research is the role of business networks in assisting knowledge transfer and sharing processes not only between different organisations but also within them, between departments. Since 1965, researchers and academics have adopted similar approaches when investigating organisational networks (Aldrich and Sakano 1995; Birley et al. 1991; Cross et al. 2001; Wenger et al. 2002; Zhao and Aram 1995), however this work concludes that there remains scope to improve the effectiveness of these networks.

\section{Intellectual capital in terms of collaborative knowledge networks}


Intellectual Capital is widely used to represent the value of a company when referring to its intangible assets. It can also be defined according to Nahapiet and Ghoshal (1998, p.245) as "the knowledge and knowing capability of a social collectivity, such as an organisation, intellectual community, or professional practice". Examining the formation of Intellectual Capital as stated by Newell et al. (2002), we can see that four parts are included under that term. These are the Customer, Structural, Human and Social Capitals. At first sight, it might seem awkward that humans have been represented separately as it is not possible to price tag people and measure their effectiveness and skills. But when talking in terms of business, humans have assets and must be controlled by strategies in order to keep them engaged (Coff 1997). Characteristics of these assets could be people's skills, knowledge, abilities and personal relationships (Coff 1997). It could also include behavioural actions as well as the effort, mental or physical, they consume towards a solution to a task (Kidwell and Bennett 1993). Social Capital mainly refers to trust and mutual respect that employees have among each other and their external environment (Leana and van Buren III 1999). As examined by Cox and Thompson (1997) through the application of the Relational Competence Analysis framework trust cannot be enforced and must be gained over time. So when referring to strategies needed in order to protect the intellectual capital of an organisation, we can clearly identify the importance of informal networks which enhance information and knowledge flows within organisations. As Cross et al. (2001) observe:

"By analyzing the dimensions of relationships that precede or lead to effective knowledge sharing, we can offer more precise ways to improve a network's ability to create and share knowledge. [...] On a more conceptual level, the combined network view offers unique purchase on the elusive concept of organizational learning". 
(Cross et al. 2001, p.118-119)

In light of this observation it is easier to understand the dynamics of today's social networks which can increase importance to effectiveness of business processes. It is stated that, in order to develop a knowledge sharing culture, you must rely on people's minds and willingness to learn and succeed. This focus on human performance illustrates the importance of the human value for a company and recognises the fact that despite the number of sophisticated tools a business may have, it is necessary to share and discuss issues and ideas with others (Nonaka 1991; Nonaka and Takeuchi 1995).

\section{Background on knowledge sharing communities}

Amid unstable economic conditions, greater focus needs to be put in organisations on improved methods of retaining and storing valuable knowledge, so that it can be easily retrieved and used in the future.

"In practical terms, there are only two types of strategies to protect this type of knowledge: retention policies and the circulation of knowledge. Retention policies are more clearly understood. Circulation of knowledge strategy relates to actively developing mentoring [...] and fostering teamwork \& communities of practice". (Terra and Angeloni 2005, p.7)

Hence, an ideal way of acquiring knowledge and sharing information and advice is by participating in a community of practice. Drawing on the seminal work of Wenger et al. (2002, p.4), communities of practice are "groups of people who share a concern, a 
set of problems or a passion about a topic, and who deepen their knowledge and expertise in this area by interacting on an on-going basis". Given this definition it can be seen that a community of practice is a process of participation and evolution where people share information, insight and advice, help each other solve problems and ponder common issues, explore ideas and act as sounding boards (Wenger et al. 2002).

"Communities of practice are not a new idea. They were our first knowledge-based social structures, back when we lived in caves [...] and have continued to proliferate to this day in every aspect of human life".

(Wenger et al. 2002, p.5)

Nevertheless, the accumulation of knowledge can be achieved either through the creation of tools, standards, manuals and other documents or simply by developing a tacit understanding (Nonaka 1991). Participants are "informally bound by the value they find in learning together" (Wenger et al. 2002, p.5), confirming Orlikowski's (2002, p.249) claim that "knowing is not a static embedded capability or stable disposition of actors, but rather an on-going social accomplishment, constituted and reconstituted as actors engage the world in practice". Wenger et al. (2002, p.5) also put emphasis on the long term development of a community of practice. Specifically they claim that over time, people "develop a unique perspective on their topic as well as a body of common knowledge, practices and approaches. They also develop personal relationships and established ways of interacting. They may even develop a common sense of identity". Moreover, the learning that takes place in communities of practice is not just situated learning but "generative social practice" (Lave and 
Wenger 1991, p.35), i.e., learners move from newcomers to experts as they become more engaged and active in the community of learning. Therefore, the development of a community is especially important in multinational organisations; boosting internal communications and individual capabilities, and can be viewed as an ongoing performance evaluation for employees.

Regarding the formation of a community of practice, there is no set way of achieving it. They can be small or big, long lived or short lived, co-located or distributed, homogeneous or heterogeneous, spontaneous or intentional as well as unrecognised to institutional (Kislov et al. 2011, p.2). Wenger et al. (2002, pp.27-29) noted that the structural model of a community of practice is a combination of three fundamental elements: A domain of knowledge, a community of people and the shared practice that they are developing to be effective in the domain. Specifically, a well-defined domain legitimises the community by affirming its purpose, inspires members to contribute and participate and guides members' learning by creating a sense of common identity. The community creates the social fabric of learning; it fosters interactions and relationships based on mutual respect and trust and encourages a willingness to share ideas, expose one's ignorance, ask difficult questions and listen carefully. Last but not least, the practice is a set of frameworks, ideas, tools, information, styles, language, stories and documents that community members share. Moreover, Wenger et al. (2002, p.51) identified seven principles for cultivating communities of practice: Design for evolution; open a dialogue between inside and outside perspectives; invite different levels of participation; develop both public and private community spaces; focus on value; combine familiarity and excitement; create a rhythm for the community. Hence, it is apparent that these knowledge-sharing 
structures not only have an important and central role in business but are also a key to success in a global knowledge economy that can create value and improve performance (Lesser and Storck 2001).

"Cultivating communities of practice in strategic areas is a practical way to manage knowledge as an asset, just as systematically as companies manage other critical assets. [They] connect people from different organizations as well as across independent business units. [...] They knit the whole system together around core knowledge requirements".

(Wenger et al. 2002, p.6)

Zboralski (2009) noted that communities of practice can provide a suitable environment to share or exchange knowledge between different groups in an organisation. Also, by sharing aspirations and ideas, they improve business outcomes and foster participation in organisational tasks such as recruitment and selection processes of employees adding short and long term value to organisations and community members.

Furthermore, Birley et al. (1991) highlight that small organisations coming from different cultural backgrounds can shape different styles of networks (both external and internal) based on their regional and national characteristics. For example, it was noted from their case study that organisations based in the USA have created a wider range of knowledge networks (9.5 members on average) compared to companies based in other countries, despite the low frequency rate of their meetings (10 meetings per month). In contrast, the Japanese companies which have devoted 
the smallest amount of time in developing knowledge networks compared to all other countries (7.9 hours per week), have managed to build the most well connected knowledge networks with only a limited number of relationships (ties) among the members of the network (Aldrich and Sakano 1995). However, despite the fact that these figures represent small organisations, networking range and intensity are deemed particularly important in the growth process of multinational organisations (Zhao and Aram 1995). Also, although networking activities may have different cultural roots, organisational success is influenced by the same principles of networking (Zhao and Aram 1995). Therefore, many multinational technology intensive organisations are trying to develop holistic knowledge sharing communities in order to enhance networking opportunities and improve the overall knowledge culture of their company. Nevertheless, there are a plethora of cases in which they fail to deliver cost effective solutions and support knowledge transfer, arguably due to the lack of incentives for sharing and creating networks. Specifically, the literature has highlighted several cases, including PharmaCorp's inflexible KM strategy (Braganza and Möllenkramer 2002), SoftwareCo's ineffective knowledge transfer mechanisms (Israilidis and Jackson 2012) and the London Ambulance Service failure (Sommerville 2006).

Wenger et al. (2002, pp.140-148) highlighted a number of roadblocks that organisations typically face when cultivating a knowledge sharing community. Specifically, the temptation of ownership can be detrimental to the domain and arrogance can bring imperialistic, narcissistic, marginal and factional beliefs; the bond between community members may become too tight, leading to problematic and toxic relationships. Cliques may arise, and the presence of co-dependent, disconnected 
and localised communities has the potential to result in less diversity of perspectives within the group. Finally, the cost of an efficient practice can blind practitioners to seeing what fits in their paradigm and what doesn't. A single-minded focus on documentation and failure to develop and deepen practice can lead to organisational amnesia, dogmatism and mediocrity.

Although these are not meant to form an exhaustive list, they represent issues that can hinder the effectiveness of a knowledge management effort, costing organisations time, money, resources and - perhaps, most importantly - their ability to effect meaningful business results (Jafari et al. 2007). Thus, particularly within technology intensive and geographically dispersed industries such as the Aerospace and Defence, organisations should develop holistic knowledge networks in order to benefit from knowledge residing in different parts of the organisation, as well as to improve communication in solving business challenges.

\section{Research methodology}

This research adopted a case study approach examining knowledge sharing networks at all levels of the workforce. Yin (1994) defined this approach as an embedded design which he believes is increasingly popular within single case studies and provides a rigorous and valid result. Cavaye (1996) noted that the general focus of case study research is on the in-depth exploration of a phenomenon and its context. This is also noted by Walsham (1995) who highlights that single cases allow deeper investigation of phenomena and result in richer descriptions and understandings of the studied phenomenon. However, case studies are exposed to 
the accusation that they are unscientific. This is also emphasised by the policy of using case study findings to form generalisations. Generalisations are based on the local construction of meaning and local rules for behaviour (emic viewpoint) and the analysis of data with a strong link to the reality of people's experiences, therefore caution has to be exercised to avoid over generalisation. Bryman (1988) highlights the way the technique is used and expresses concerns over the representational scope within the case study that can affect the external evaluation of the validity of the study and its findings.

The case-study organisation is one of the largest military contractors in the world which employs over 100,000 people across the globe. The company is ranked within the top 10 of the major global aerospace and defence indexes including the Defence News, Forbes2000 and Stockholm International Peace Research Institute (SIPRI) top 100. The company's employees are highly skilled within their respective field and the organisation has attempted to create an environment specifically suited to knowledge exchange, transfer and sharing.

The objectives of the data gathering were to analyse the viability of organisational networks and investigate their contribution to the business based on different areas of impact. Given the current literature on collaborative networks and communities of practice (Wenger et al. 2002, McDermott 2002, Gongla and Rizzuto 2001, and Hsieh et al. 2009) and the work of Paulk et al. (1995) on the Capability Maturity Model, five different areas of impact were considered in this study and used in the following context: 
- Strategic alignment explored the clarity of the community's charter and strategy to support organisational goals.

- Governance focussed on whether the community's structure is recognised by management, and whether consistent governance mechanisms to ensure sufficient time, funding and resources are available to the community.

- Collaboration analysed whether members within a community are working together, sharing success stories and embedding learning into the way the community works.

- Information technology examined whether there is a wide range of common collaborative tools and corporate infrastructure available to support and help the community learn.

- Valuable outputs identified whether the community acts as an agent of change, benchmarking knowledge process indicators and engaging in work that is changing what the business does.

Additionally, in order to capture the full scope of networking performance and identify the strengths and weaknesses of such heterogeneous knowledge structures, it is common practice amongst maturity models to group values into levels for statistical treatment. Thus, all the above areas were sectioned into six different levels which were associated in an ascending order as depicted in Figure 1 (Level 0 indicated the lowest level and Level 5 the highest). Each maturity level represented an extension of the previous level in terms of the documentation, implementation and impact of each area reported, namely strategic alignment, governance, collaboration, information technology and valuable outputs. Hence communities of practice that 
score a higher maturity rating are in general considered to be more structured, optimised and well-managed. By using a modified version of the capability maturity model as a performance metric and diagnostic tool, a comprehensive range of aspects in relation to business networks as noted in the literature (such as the role of technology, intellectual capital, collaborative behaviours, performance and outcomes and communities of practice) were analysed and a practical way of measuring their contribution against a fixed set of criteria was provided.

\begin{tabular}{|c|c|}
\hline Maturity Level & Description \\
\hline 0 (non-existent) & The practice does not exist in the organisation \\
\hline 1 (initial, informal) & $\begin{array}{l}\text { The practice within the organisation is ad hoc, } \\
\text { and with no established standards or policies }\end{array}$ \\
\hline 2 (repeatable, formalised) & $\begin{array}{l}\text { The practice has been established, documented } \\
\text { and possibly resourced, but its actual usage is } \\
\text { isolated }\end{array}$ \\
\hline $\begin{array}{l}3 \text { (defined, partially } \\
\text { implemented) }\end{array}$ & $\begin{array}{l}\text { The practice is being used but its usage is not } \\
\text { standard, pervasive, consistent or measured }\end{array}$ \\
\hline 4 (managed, implemented) & $\begin{array}{l}\text { The practice is fully implemented and consistently } \\
\text { applied. Metrics have commenced }\end{array}$ \\
\hline 5 (optimised) & $\begin{array}{l}\text { The practice is measured and continuously or } \\
\text { regularly reviewed against best practice or } \\
\text { improvement goals }\end{array}$ \\
\hline
\end{tabular}

Figure 1: The six different levels of the capability maturity model. 
The empirical data reported in this study were generated by a participatory workshop which was organised by the KM group of the organisation at the company's headquarters, and in which the researcher was actively involved as participant and observer. It is worth mentioning at this point that the organisation was very keen to organise such events, however no corrective or preventive actions appeared to be taken subsequent to the workshops, even if new KM dysfunctions were discovered. Also despite the limited time availability of the participants and the relatively simple organisation of the event, a systematic method was adopted (further discussed in this section), and the participants engaged fully with the exercise.

The workshop involved twenty-two employees from fourteen different organisational departments, including military air and information, avionics, maritime, land, electronic systems, shared services, business winning, security and space, amongst others. The participants were self-selecting based on their decision to participate voluntarily in knowledge-exchange networks, and were involved in several different communities or networks. Some of their main activities included sharing good practice, connecting people to people, supporting growth, stimulating innovation, auditing current systems and enhancing services, amongst others. This in itself enhanced the validity of the outcome as the results were reflecting not only specific divisions, project groups or self-directed teams but the organisation as a whole.

Krueger (1994, p.11) noted that workshop-style discussions are effective because they tap into the human tendency to develop attitudes and perceptions by interaction with people and that "people may need to listen to opinions of others before they form their own personal viewpoints". Moreover, workshop-style discussions were 
considered an appropriate choice for this study because of their ability to produce concentrated amounts of data on a specific topic while allowing the authors to "obtain deeper levels of meaning, make important connections, and identify subtle nuances in expression and meaning" (Stewart and Shamdasani 1990, p.16). All of the above, however, must be viewed in light of the inherent limitations associated with this method, including the small number of respondents that participated, the limitations on generalisability to a larger population, and the bias of the researchers' influence and interests.

At the start of the workshop, the researcher recorded each participant's basic details (i.e. name, department, role, network they were involved in). In addition, information was gathered regarding their role within the community or network in which they were involved in identifying supportive or growth-oriented approaches. The participants were given cards illustrating the maturity model and were given sufficient amount of time to study the different maturity levels and areas of impact of the model before reporting their findings back to the rest of the group.

During the workshop, each participant represented a different community or network in the case-study organisation (unit of analysis) and discussed about their viability and performance in the business. For each area of impact listed, participants were asked to indicate where they thought their network or community place was within the model (i.e. current state) as well as what their desired state/target would be. Only one rating was accepted as valid since a community or network cannot have more than one maturity level at a single point of time. The information exchanged was recorded in written format (seminar transcripts) by the authors during the event, and 
was later coded and analysed based on the five aforementioned areas of impact. Percentages of each level within each area of impact were also calculated to visualise the maturity of networks across different aspects.

\section{Results}

The data gathered from the workshop-style discussions are analysed and presented in this section. In total, twenty-two employees participated in the workshop, representing one organisational network or knowledge exchange community each. The sample included seventeen men and five women and as mentioned in the Methodology, the participants were working across fourteen different departments and had different roles within the business.

From the analysis, the results highlighted that in relation to strategic alignment of each network or community, the vast majority of the communities (fifteen communities out of eighteen - four participants chose not to submit ratings) had demonstrated a lack of knowledge transfer and exchange mechanisms, indicating the difficulty in communicating and expressing their ideas to the management and their executives. Six communities were found to be at Level 1, nine communities were placed in Level 2, and only three were found to be within the acceptable standard of Level 3. However, by further analysing the desired state (i.e. target) of each community, it was found that their members had strong motive to achieve better scoring and see them within the top three levels of the model. In general, predicting the failure-prone path to corporate strategy, i.e. contributing factors leading to poor knowledge sharing and collaboration along with their associated 
trajectories, could bring additional benefits, such as better risk management and improved performance. Particularly, the analysis of trajectories could represent the knowledge-state of an organisation, and can be used to eliminate unhealthy levels of ignorance while preventing dysfunctional $\mathrm{KM}$ scenarios in the workplace. For example, it was apparent from this study that communities within high maturity levels (e.g. Level 4 or Level 5) have a clear charter and strategy that could help address critical business issues and support organisational goals.

Furthermore, four of the participants placed their communities in Level 1 and three in Level 3 concerning the governance and structure of each network or community. Interestingly, more than half of the sample (eleven communities) claimed to be in Level 2 with little flexibility to adjust to any other level based on the participants' remarks.

In respect to the collaboration mechanisms of each network or community, the picture differs compared to the other categories presented. This is due to the observation that communities often have the notion of sharing and collaborating as a basic principle within their strategy. Thus, one community was found to have the ability to share ideas and collaborate with other communities, six were found to be at an acceptable collaborative level (Level 3), six were placed in Level 2 and only five showed signs of no collaboration and knowledge sharing.

On the subject of information technology, it was highlighted that four communities had little or no awareness of techniques and tools to communicate and share knowledge; two communities were using a range of tools including video, voice, web- 
conferencing, team-rooms and instant messaging and surprisingly, ten communities were found below the acceptable standard (Level 2). In the case-study organisation, software applications (or tools) appeared to be poorly architected, designed or developed in general, and employees were mandated to use them because they were embedded within an organisations process and rules, even though better applications may exist for the same task. This situation however could lead to the creation of systems with inadvisable user requirements and inappropriate interfaces; therefore they may inevitably fail to support basic knowledge management processes, including knowledge sharing, transmission, and acquisition, among others.

Last but not least, regarding the valuable outputs of each network or community, the majority of the sample (twelve communities) was found to have no clear evidence of how their membership can help to solve daily work problems, making benefits to the organisation fragmented and hard to substantiate. Only one community performed to an acceptable standard (Level 3), while three were rated at Level 1, resulting in the inability of communities to act as an agent of change and helping develop expertise in other business areas.

Given the above findings, it appeared that within the case study organisation, selfcreated (spontaneously created or emergent) communities of practice lacked basic knowledge exchange mechanisms and hence were not inclined to produce new knowledge and foster innovation. All of the networks examined had something to learn but not necessarily something to share. This appears to be due to the fact that within these communities goals were not clearly stated and members were not 
engaged in developing good practice to help solve business challenges. An interesting statement expressed by a staff member showed that not engaging in developing good practice to help solve business challenges could contribute to the overall knowledge confusion in the organisation:

"I'm not part of any community and there are no communities or networks that I know of".

In addition, it appeared that the network leaders were not given sufficient time for their role while funding was limited for supporting face-to-face activities that address labour issues. The time issue, or more explicitly the notion of 'I can't spend time for KM unless I have a budget code', was often observed in this study and is likely to be a major obstacle for managing knowledge effectively. Figure 2 provides a visual representation of the data gathered during the workshop. 


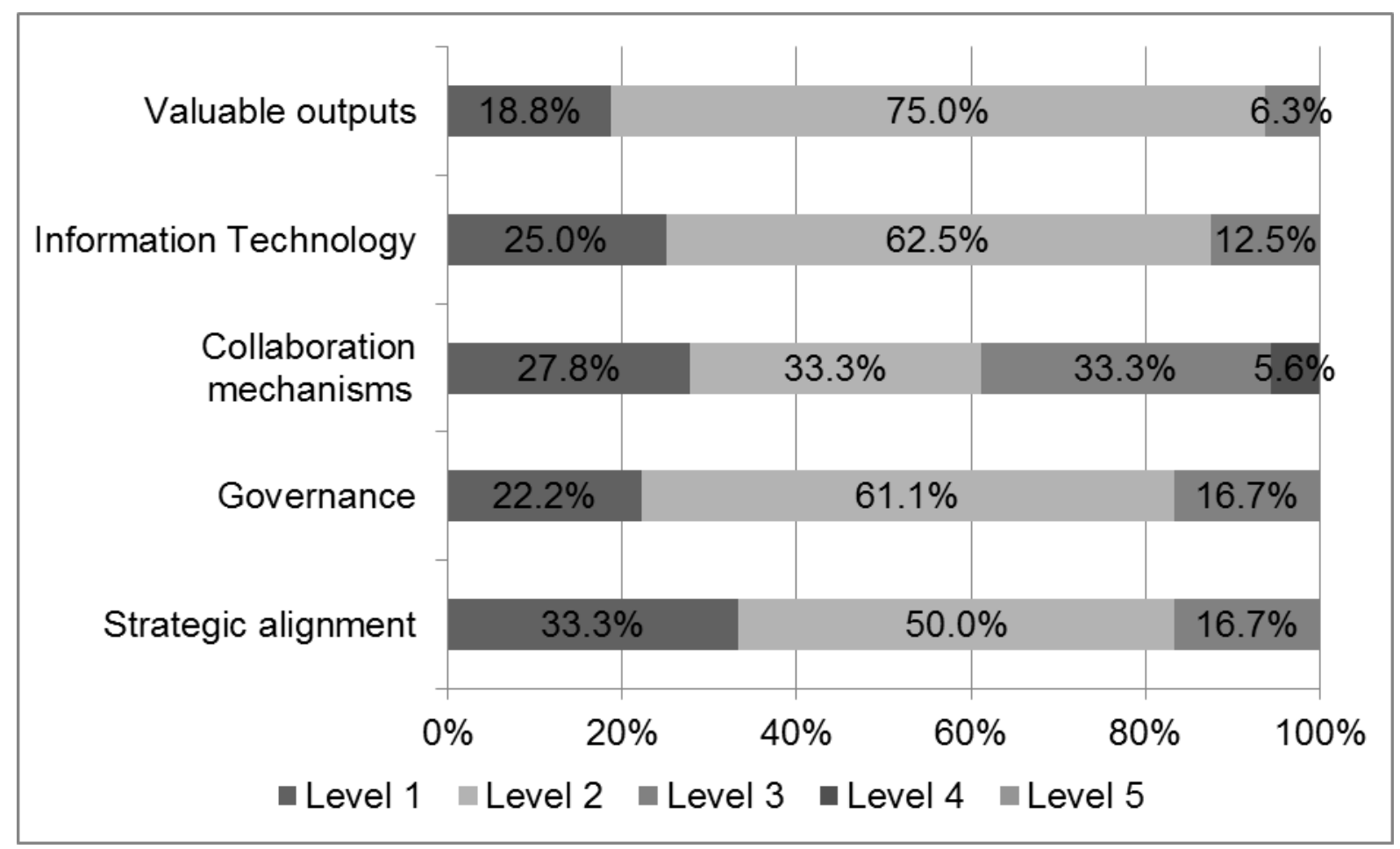

Figure 2: The results based on the five areas of impact in managing business networks

\section{Discussion}

The results of the study support previous research carried out by Wenger et al. (2002), who identified a number of roadblocks that organisations typically face when cultivating a knowledge sharing community, and that can hinder the effectiveness of a corporate knowledge management effort. For example, by not making clear each community's responsibilities and tasks the situation within departments tends to turn into a chaotic, disorganised and messy environment. Additionally, flexibility and agility being the main principles of a knowledge sharing community are transposed into resistance, something that can lead to problems and affect the business's operations and functionalities. 
Also, it was apparent from the study that to support the sharing of knowledge in communities, organisations should provide a holistic set of resources. As Hildreth and Kimble (2004) report, it is essential to identify suitable people to fill community roles and manage the community's activities, organise activities to bring the community together in meetings and events, invest in technological innovations to facilitate the flow of information between activities and finally manage the explicit knowledge that the community creates to increase organisational performance. However, in addition to the above research implications, this study has also highlighted the importance of maintaining a strategic focus in developing knowledge sharing communities and networks. Specifically, the poor communication strategy between management and the employees has highlighted the chaotic knowledge environment existing in various departments. Hence, several advantages derived from the existence of collaborative networks are not explored and tacit knowledge is not circulated effectively across the organisation. This in itself reduces the creation and promotion of new knowledge which is essential for the company's competitiveness (Leonard and Sensiper 1998).

Moreover, in regards to the strategic focus of each community, it was interesting to note that most communities had no clear connection to corporate strategy, no agreed way of working and limited stakeholder communications. Also the employees highlighted that the organisation was unaware or uninterested in the future of their community. However, as the findings suggest, staff members would appreciate any support from the management and would prefer to see their community embedded in the business strategy and mentioned in strategic documents. Also, when analysing 
collaborative behaviours, it was concluded from the research that knowledge management groups rated a better scoring compared to other non-knowledge sharing related networks. This can also be justified given that knowledge communities have as basic principle within their strategy the notion of sharing and collaborating for the promotion of know-how and expertise across different disciplines.

Liedtka (2000) links communities of practice to an organisation's competitive advantage and ability to deliver on-time customer performance. However, regarding the promotion of best practice across the organisation, it is essential to recognise the importance of knowledge sharing communities by not giving them day-to-day mundane tasks but only energising duties which will motivate the employees and develop a learning place where individuals will be able to share their experiences and expertise. Also, both informal and formal business networks should be supported by management to enhance knowledge sharing between different groups within multinational organisations and knowledge sharing policies should be reviewed on an on-going basis in order to create a robust network of networks while acknowledging the importance of smaller and more isolated knowledge exchange communities. This will allow each of the 'silo' networks to connect with the formal business communities and "increase the sharing of lessons learned, the exchange of insights and ideas and the transfer of expertise and hand-on experience" (Hildreth and Kimble 2004, p.2) within the business. It must be noted at this point however, that despite the importance of periodic reviews and following up on the conclusions of knowledge sharing events, the case-study organisation appeared to be unaware or uninterested in the potential of business communities by not sufficiently resourcing 
the $\mathrm{KM}$ group to undertake regular knowledge exchange activities, leading to low interest in learning from the experience of others and sharing success stories between business units.

\section{Conclusion}

Drawing upon the empirical research undertaken within the case-study organisation, this paper discusses ways of increasing the productivity and performance of organisational networks within multinational corporations, and explores the heterogeneous knowledge structures of collaborative knowledge communities, while analysing their strengths and weaknesses. It also identifies dysfunctional KM communities and examines the mechanics of business networks in technology intensive settings. Little of this discussion is captured by the current KM literature; hence it is argued that this paper has shed new insights into KM in the Aerospace and Defence industry. Particularly, emphasis should be put on the development of holistic knowledge sharing communities within multinational organisations, as this is especially important for boosting internal communications and individual capabilities, and can be viewed as an on-going performance evaluation for employees and large organisations.

The study's findings show that cultivating knowledge sharing communities should be managed with great care in order to gain competitive advantage through more effective knowledge management strategies. This leads us to conclude that there could be benefit in re-examining managerial strategies on a periodic basis by providing additional resources and support to knowledge sharing communities. This 
viewpoint of acknowledging the importance of business networks, if successfully incorporated within a company's KM strategy, will not only facilitate and enhance knowledge storage and transmission processes but will also undoubtedly play a vital role when referring to a company's efficiency, productivity and overall performance. Another conclusion is to align the aims of smaller communities with the corporate strategy for the benefits of the organisation. For example, it was apparent from the research that networks classified within the domain of high level knowledge (sharing networks) could produce new knowledge and foster innovation within the business. Finally, this paper suggests that each of the 'silo' collaborative networks should be connected with the formal business communities to alleviate knowledge-related problems and create a dynamic knowledge sharing culture.

The study reflects the experience of large multinational organisations and much remains to be done in analysing small and agile corporate environments. Also, further work on analysing the characteristics that make knowledge sharing communities effective would be beneficial. Finally, the informal nature of knowledge sharing merits additional study to help to define further the characteristics of a successful collaborative network.

\section{References}

Aldrich, H., Rosen, B. and Woodward, B. (1987) The impact of social networks on business foundings and profit: A longitudinal study. In Frontiers of Entrepreneurship Research. Wellesley, MA, Babson College, 154-168. 
Aldrich, H. and Sakano, T. (1995) Unbroken ties: How the personal networks of Japanese business owners compare to those in other nations. In Fruin, M. (Eds.) Networks and Markets, Pacific Rim Investigations, New York: Oxford Press, 17-45.

Birley, S., Cromie, S. and Myers, A. (1991) Entrepreneurial Networks: Their Emergence in Ireland and Overseas. International Small Business Journal, 9(4), $56-73$

Braganza, A., and Möllenkramer, G. J., 2002. Anatomy of a failed knowledge management initiative: lessons from PharmaCorp's experiences. Knowledge and Process Management, 9(1), 23-33.

Bryman, A. (1988) Quantity and quality in social research. London: Routledge.

Burt, R. (1992) The Social Structure of Competition. In Nitkin, N. and Eccles, R. (Eds.), Networks and Organizational Structure, Form and Action, Harvard Business School Press, Boston, 57-91.

Cavaye, A.L.M. (1996) Case study research: a multi-faceted research approach to IS. Information Systems Journal, 6(3), 227-242.

Coff, R. (1997) Human Assets and Management Dilemmas: Coping with Hazards on the Road to Resource-Based Theory, Academy of Management Review, 22(2), $374-402$

Cox, A. and Thompson, I. (1997) 'Fit for purpose' contractual relations: determining a theoretical framework for construction projects. European Journal of Purchasing \& Supply Management, 3(3), 127-135.

Cross, R., Parker, A., Prusak, L. and Borgatti, S.P. (2001) Knowing what we know: supporting knowledge creation and sharing in social networks. Organizational Dynamics, 30(2), 100-120. 
Gongla, P. and Rizzuto, C. R. (2001) Evolving communities of practice. IBM Systems Journal, 40(4), 842-862.

Granovetter, M. (1973) The Strength of Weak Ties. American Journal of Sociology, 78(6), 1360-1380.

Granovetter, M. (1985) Economic Action and Social Structure: The Problem of Embeddedness. American Journal of Sociology, 91(3), 481-510.

Hansen, M.T. (2002) Knowledge Networks: Explaining effective knowledge sharing in multiunit companies. Organization Science, 13(3), 232-248.

Hildreth, P. and Kimble, C. (2004). Knowledge Networks: Innovation through Communities of Practice. London: Idea Group Publishing.

Hodgson, G. (1988) Economics and institutions. Oxford: Polity Press.

Hsieh, P. J., Lin, B., and Lin, C. (2009) The construction and application of knowledge navigator model (KNM): An evaluation of knowledge management maturity. Expert Systems with Applications, 36(2), 4087-4100.

Israilidis, J. and Jackson, T. (2012) Examining information and knowledge processes to enhance best practices in agile knowledge intensive environments. Knowledge and Process Management, 19(4), 171-179.

Jafari, M., Akhavan, P., Nour, J.R. and Fesharaki, M., 2007. Knowledge management in Iran aerospace industries. Aircraft Engineering and Aerospace Technology: An International Journal, 79(4), 375-389.

Kidwell, R.E. and Bennett, N. (1993) Employee propensity to withhold effort: A conceptual model to intersect three avenues of research. Academy of Management Review, 18(3), 429-456.

Kislov, R., Harvey, G. and Walshe, K. (2011) Collaborations for Leadership in Applied Health Research and Care: lessons from the theory of communities of practice. Implementation Science, 6(64), doi:10.1186/1748-5908-6-64. 
Lave, J. and Wenger, E. (1991) Situated Learning: Legitimate Peripheral Participation. Cambridge: Cambridge University Press.

Leana, C.R. and van Buren III, H.J. (1999) Organizational social capital and employment practices. Academy of Management Review, 24(3), 538-555.

Leonard, D. and Sensiper, S. (1998) The role of tacit knowledge in group innovation. California Management Review, 40(3), 112-132.

Lesser, E.L. and Storck, J. (2001) Communities of practice and organizational performance. IBM Systems Journal, 40(4), 831-841.

Liedtka, J. (2000) Linking competitive advantage with Communities of Practice. In Lesser, E.L., Fontaine, M.A. and Slusher, J.A. (Eds.), Knowledge and communities, Oxford: Butterworth-Heinemann.

Marshall, A. (1965) Principles of economics. London: Macmillan.

McDermott, R. (2002) Measuring the impact of communities: How to draw meaning from measures of communities of practice. Knowledge Management Review, 5(2), 26-29.

Nahapiet, J. and Ghoshal, S. (1998) Social capital, intellectual capital and the organizational advantage. Academy of Management Review, 23(2), 242-267.

Newell, S., Robertson, M., Scarborough, H., and Swan, J. (2002) Managing knowledge work. Basingstoke: Palgrave.

Nonaka, I. (1991) The knowledge creating company. Harvard Business Review, 69(6), 96-104.

Nonaka, I. and Takeuchi, H. (1995) The Knowledge-Creating Company: How Japanese Companies Create the Dynamics of Innovation. New York: Oxford University Press. 
Orlikowski, W.J. (2002) Knowing in practice: Enacting a collective capability in distributed organizing, Organization Science, 13(3), 249-273.

Paulk, M. C., Weber, C. V., Curtis, W. and Chrissis, M. B. (1995) The Capability Maturity Model: Guidelines for improving the software process. NewYork: Addison-Wesley.

Sommerville, I., 2006. Software engineering (8th edition). Harlow, UK: Pearson Education.

Sun, P. Y. T. and Scott, J. L. (2005) An investigation of barriers to knowledge transfer. Journal of Knowledge Management, 9(2), 75-90.

Terra, J.C. and Angeloni, T. (2005) Understanding the difference between Information Management and Knowledge Management. [WWW document] http://www.providersedge.com/docs/km_articles/Understanding_the_Difference_B etween_IM_and_KM.pdf (accessed 04 February 2011).

Walsham, G. (1995) Interpretive case studies in IS research: nature and method. European Journal of Information Systems, 4(2), 74-81.

Wenger, E., McDermott, R. and Snyder, W. (2002) Cultivating communities of practice. Cambridge, MA: Harvard Business School Press.

Yin, R.K. (1994) Case study research - Design and methods, 2nd edition. Thousand Oaks, CA: Sage.

Zboralski, K. (2009) Antecedents of knowledge sharing in communities of practice. Journal of Knowledge Management, 13(2), 90-101.

Zhao, L. and Aram, J. (1995) Networking and growth of young technology-intensive ventures in China. Journal of Business Venturing, 10(5), 349-370. 